\title{
Two sides of the same coin? Internationalisation and employability: Students' perceptions of employability and career outcomes from International Studies
}

\author{
Beate Mueller ${ }^{1}$ and Julie Robert ${ }^{2}$ \\ Corresponding author: Beate Mueller (beate.mueller.sydney@gmail.com) \\ ${ }^{1}$ School of International Studies and Education, University of Technology Sydney: http://orcid.org/0000-0001- \\ 6062-450X \\ ${ }^{2}$ School of International Studies and Education, University of Technology Sydney: https://orcid.org/0000-0001- \\ $\underline{6852-2137}$
}

\begin{abstract}
The Australian higher education sector has promoted internationalisation opportunities for students, including through international studies (IS) courses that entail language and culture study and international exchange. Educators promote internationalisation for many reasons, including enhanced employability, and international studies degrees are increasingly offered in combination with professional courses. Students, however, do not necessarily share in the belief that international opportunities and language study will increase their employability. A thematic analysis of statements $(n=223)$ supplied on student applications to withdraw from combined international studies courses in favour of single professional degrees, reveals that students fail to see employability benefits and may even perceive their international studies course as a professional liability. Understanding these beliefs can allow educators to more effectively promote the value of not only international studies degrees, but also language and culture study and exchange opportunities, and to counter some of the myths that prevent students from undertaking international opportunities.
\end{abstract}

Keywords employability, International Studies, language learning, student perceptions, study abroad

\section{Introduction}

Universities' internal quality and viability control processes, to say nothing of national reputational data and global rankings, increasingly measure the success of degree programs using factors relating to graduate employability. ${ }^{1}$ Employability discourses have, often through the higher education (HE) sector's own marketing efforts, trickled down to students and undergraduates' influencers (parents, teachers, career counsellors). Employability, defined by Yorke (2006) as a set of achievementsskills, understandings and personal attributes-that makes graduates more likely to gain employment and be successful in their chosen occupations, which benefits themselves, the workforce,

\footnotetext{
${ }^{1}$ New Australian performance-based funding protocols, introduced in 2019, further use graduate employment outcomes as a way to calculate a HE provider's overall effectiveness, and thus government support. 
the community and the economy (p. 8), has accordingly become an important factor for students in decisions about their education.

At the same time as employability has exerted its influence on $\mathrm{HE}$, the sector has also adopted ambitious internationalisation agendas. These endeavours, which encompass a range of initiatives including inbound and outbound student mobility, full-degree international recruitment, language and intercultural learning opportunities, international internships and partnerships - contribute to social change, global citizenship, community engagement and graduate employability in that they align with the role that universities play in educating skilled personnel capable of making positive contributions in rapidly changing contexts (Crossman \& Clarke, 2010, p. 601). A key facet of internationalisation agendas is the promotion of international experiences for domestic students, often through international internships or study abroad. In Australia, as in other contexts, institutions have responded by creating short-term programs (of up to 8 weeks), although the more traditional semester or year abroad are still popular (Department of Education Employment \& Training, 2019). Government support for student mobility, including through New Colombo Plan funding for the Asia-Pacific, has improved access and encouraged participation.

One of the ways Australian universities have responded to the twinned imperatives of employability and internationalisation has been to offer combined degrees in professional fields (business, communications, law, etc.) and international studies, a generic term for an area-studies course that encompasses the transferable skills of an arts qualification, foreign language and culture study and a substantial period of study abroad. While these degree combinations serve universities' goals well, student perceptions about the holistic value of such programs and their constituent parts is mixed, especially in relation to employability. Aligning student perceptions of employability as a result of internationalisation with the evidence is necessary if IS courses are to fulfil their function as a popular way for universities to simultaneously improve these two strategic goals.

This study seeks to identify and remedy the discrepancy which exists between the way in which HE has developed combined IS courses to promote employability and internationalisation and students' views on the likely effectiveness of this strategy via an analysis of students' negative perceptions of the value of an additional undergraduate-level international studies (IS) qualification. A large Australian university with a strong employability and internationalisation focus serves as a case study. A review of relevant aspects of the literature on choices in $\mathrm{HE}$, with a focus on employability, language learning and study abroad precedes the presentation of findings. These reveal that the perceived value of IS with respect to employability, inclusive of foreign language study and study abroad, is subject to considerable negative opinion, some in contradiction of the evidence, for students. The challenge facing educators who champion internationalisation is therefore one of understanding and countering these beliefs so that internationalisation is no longer frequently perceived as coming at the cost of employability.

\section{Literature review}

Decision-making around HE and course choices is part of life-long career development learning that comprises complex processes that are influenced by many considerations and stakeholders (Mcllveen et al., 2011). Starting in secondary school, where the influence of family and schools is as important as financial considerations, career aspirations and personal interest (Leach \& Zepke, 2005), this process continues well into the first years at university (Baik, Naylor, \& Arkoudis, 2015) and is subject to varying external and internal influences. This review surveys the principal bodies of literature relevant to IS - which includes language and study abroad and their impact on the development of employability competencies. The Australian example, especially as it is relevant to IS, is highlighted throughout, although general trends are also identified. 


\section{Employability and HE choices}

Career considerations play an increasingly important role in the HE decision-making process, owing in part to rising tuition costs (Baik et al., 2015; Greenbank, 2011) and changing labour markets (Accenture, 2014). Closer to matriculation, students consider individual courses and might project how each will provide a return on their educational investment (Leach \& Zepke, 2005; Holmes, 2013). Over the last two decades, Australian university students cited intrinsic interest in their field of study (96\%), improving their job prospects (87\%), developing their talents and creative abilities (77\%), training for a specific job (77\%), and fulfilment of parental expectations (41\%) as motivations for their choices (Baik et al., 2015).

Decision making, however, increasingly extends into the post-matriculation phase. Students continue to 'shop' for subjects (units) and whole courses (majors or degrees) once enrolled, with approximately 35\% uncertain about or intending to change their choice (Baik et al., 2015). Arts students are more likely to experience career indecision and anxiety compared to their peers in other professional degrees (Daniels et al., 2011; Kinash, Crane, Judd, \& Knight, 2017) with up to 15\% of students in arts degrees and one third of students in cross-disciplinary degrees enrolled primarily to delay decision-making (Baik et al., 2015). Humlum, Kleinjans, and Nielsen (2012) examining the influence of identity on career choices, also found that lower career motivations correlated with career choices for the humanities. Often, students find it difficult to find information on the value of certain degrees or degrees combinations (Parks, Mills, Weber, \& Westwell, 2017).

While professional identity formation for single degree students is relatively well established (see Trede, Macklin, \& Bridges, 2012), knowledge about field of study via a concurrent or combined degree, especially in relation to employability and professional identity formation, is comparatively understudied (Culver et al., 2011). Lock and Kelly (2020) show that dual degree students often have a less defined career goal and a lower understanding of careers linked to their chosen degrees, which reveals greater uncertainty around degree combinations. This was also echoed by Baldry, Märtsin and Eivers' (2020), examining the struggles of dual degree students to building a professional identity that combines their two degrees.

Insecurity in employment markets for graduates has prompted many to seek out courses, skills, and experiences they believe will increase their employability via specialist degrees, as students tend to narrowly associate their career-motivated decision-making with their major area of study (Arcidiacono, Hotz, \& Kang, 2012). Students' ideas about employability though are often out of sync with reality (Accenture, 2014; Australian Education International, 2010). Far from being entirely contingent upon curriculum-based activities, graduate capabilities leading to employment are developed via experiential learning opportunities such as internships and exchanges (Jackson, 2016; Jones, 2013), certain prerequisites and personal attributes (Clarke, 2018), part-time work, career advice and networking (Kinash et al., 2016).

Research into employability and internationalisation though, often either considers courses holistically (Jackson, 2016), as is the case in studies of students opting to specialise in languages, or focuses on particular experiences, such as learning abroad (Green, King, \& Gallagher, 2019; Jones, 2013). By consequence, the complexity of factors that underlie students' decision making in IS degrees with regard to employability perception and values is relatively underrepresented.

\section{Factors that influence students to study languages}

Within the Australian context, the highly prescribed nature of many undergraduate degrees, especially in professional fields, often means that elective space is limited and an additional or concurrent course, such as a combined degree or a separate diploma in languages, is one of the principal avenues for language study. Where these options are more likely to provide students with a meaningful volume of language study (one that could be relevant to employability), questions about the motivations for language study, as well as the form and volume that study takes to also 
support employability learning, must be considered. In European, Asian and American contexts, knowledge of another language is often perceived as an 'added value' (Heller \& Duchêne, 2012, p. 2) as it enriches a person's economic, academic and symbolic capital (Kramsch, 2014; Mendoza \& Phung, 2019). This valuing of languages, including in relation to employability, has nonetheless led to a differentiated ranking of languages (Heller \& Duchêne, 2012) with English being a sought-after employment-related skill for non-native English speakers (Thompson, 2017). By contrast, native English speakers, especially in predominantly Anglophone contexts, attribute less value to learning an additional language (Young, 2018).

While heritage language learning has a long history in Australia (Hajek \& Baldwin, 2020) and despite a large number of multilingual background speakers in metropolitan areas, language study in Australian schools has declined rapidly, with less than $10 \%$ of secondary students completing language study throughout high school (Moloney, 2018). Students who embrace language studies value the affordances of fluency in another language and appreciate the diverse linguistic capital linguists bring to education specifically and to society as a whole (Asia Education Foundation, 2014, p. 31). Such conclusions are nonetheless based on the minority of students who persist with language study, a choice mitigated by a lack of continuity in learning the same language/s and parental support (Munro, 2016). Students specialising in languages in university are thus more likely to be intrinsically motivated through their previous language studies (Campbell \& Storch, 2011) and less concerned about the future professional value of languages. However, recognising the value of transferable learning outcomes of language studies, more institutions are promoting the connections between languages and employability (Oakes, 2013; Fornasiero et al., 2020), a development assisted by the federal government's inclusion of languges as a priority area in 2020's 'Job-ready Graduates' legislation pertaining to university fees and funding (Parliament of the Commonwealth of Australia, 2020).

Specific questions, such as how much language knowledge is required in Australian workplaces, what other skills that are learnt through language acquisition are valued by employers and what role languages play in the $\mathrm{HE}$ and career decision-making of students nonetheless require further research. Pragmatic concerns, such as an inability to foresee oneself using the language in the future, thus have a dampening effect on the motivation to study a language at university, a factor that correlates most strongly for potential learners from lower socioeconomic backgrounds (Gayton, 2018). The value of learning additional languages is often misunderstood or insufficiently developed by students, parents and other influential stakeholders. This makes language study, especially in the context of additional or concurrent courses that do not provide a straightforward professional pathway, at the mercy of intrinsic motivations rather than an evidence base about employability.

\section{Factors that influence the choice to study abroad}

Prior to the COVID-19 pandemic, study abroad was an important part of many HE students' experience. Australian students nonetheless differ from their European counterparts in terms of experiences sought and motivations. In Europe, professional gains and language development are common motivations among Erasmus cohorts and are frequently reported in the ERASMUS impact studies (European Commission, 2014) and the UK Broadening Horizons reports (British Council, 2017). In contrast to Europe though, a greater share of Australian university students chooses shorter overseas programs and in English speaking countries or in English language of instruction programs, a decision that attests to a lower value being placed on foreign language acquisition (Daly, 2011), but that nonetheless speaks to a desire to travel and experience other cultures. Universities Australia (2016) reports that the motivations for study abroad are diffuse: it is an opportunity [for students] to challenge themselves, enhance their future job prospects, build new networks and gain independence. Participants of longer programs nonetheless reported language, intercultural skills and global awareness development as motivators (Daly \& Barker, 2005). Exchange participation in Australia also tends to be higher among humanities and business students compared to students of law, science, education, and health (Daly \& Barker, 2005), a factor that may be explained by course

Mueller, B., \& Robert, J. (2021). Two sides of the same coin? Internationalisation and employability: Students' perceptions of employability and career outcomes from International Studies Journal of Teaching and Learning for Graduate Employability, 12(2), $19-35$. 
requirements in these areas, the lack of exposure to language learning in university, or a combination thereof.

A considerable body of scholarship based on returned-students' experiences touts personal, intercultural, academic and professional benefits: enhanced personal development, skills, and knowledge (Dwyer \& Peters, 2004; Mueller, 2021); intercultural sensitivity (Medina-Lopez-Portillo, 2004); improved communicative capacity (Jackson, 2011); overall academic improvement (Cardwell, 2019); career enhancement and the acquisition of various transferrable skills (European Commission, 2014; Jones, 2013; Potts, 2015; 2018). A broadening of educational and occupational choices, lifestyle, perspectives, change in behaviours, personal and social skills are similarly listed among the long-term impacts that accrete to study abroad participants (Dwyer \& Peters, 2004; Fry et al., 2009).

Student enthusiasm and evidence of accreted benefits of study abroad are nonetheless weighed against significant and varied disincentives - financial or personal circumstances, the fear of not being able to adjust, speak the local language(s) and make new friends or worries about safety and wellbeing - which tend to apply evenly in Australia and other contexts (British Council, 2017; Cushner \& Karim, 2004; Forsey, Broomhall, \& Davis, 2012). Academic concerns about delayed course progression also dampen enthusiasm and discourage participation (Young \& Harper, 2004).

\section{Employability and the value of study abroad and languages}

As explored earlier, students' choices about HE, include broad concerns for employability. Where we previously explored the reasons for students to enrol into specific degrees or degree components, evidence of the outcomes of these components in terms of employability is also relevant. Following on from Yorke's (2006) definition, employability accrues via a combination of subject-specific and transferable skills, the latter of which are often promoted through generalist or arts degrees, including IS. Employability further comprises the networks a graduate gains through their experiences and how they use this social capital for employability purposes (Bridgstock, 2016). Learning abroad develops these networks beyond national borders.

As genuine employability is difficult to quantify though, employment numbers are often used as a proxy. Cross-cultural research suggests that the differential employment prospects of mobile and non-mobile graduates are roughly similar in Europe, the United States and Australia (European Commission, 2014; Potts, 2018). The Australian Graduate Outcome Survey (2016) reports a $4 \%$ higher full-time employment rate for students who engaged in study abroad during their undergraduate degree compared to students who did not, though the survey's methodology considers subsequent full-time study as part of this figure and does not differentiate by program duration, structure or whether students studied in English or another language. Even employment rates for mobile graduates therefore conceal many variables.

Research into study abroad participants conducted shortly after their time away show the benefits of spending a significant study period in a different country increased students' linguistic and/or cultural skills and knowledge, and allowed them to develop personal attributes and transferrable skills. These are anticipated to significantly enhance their career capital and therefore offer a potential return of their investment of time, funds, and effort relative to those who did not study abroad (Crossman \& Clarke, 2010; Potts, 2015). Australian study abroad participants overwhelmingly maintain that studying abroad helped them clarify their career direction, secure graduate employment, improve their long-term career prospects, broaden their transferrable skills (interpersonal and communication skills, teamwork, problem solving, analysis), and improve their maturity as well as academic and professional knowledge (Potts, 2015). These findings confirm earlier and current research that attribute work-related skills such as self-confidence, decisiveness, teamwork, independence, problem-solving autonomy, the ability to work with diversity and cultural awareness to study abroad (Farrugia \& Sanger, 2017; Johnson \& Anderson, 2019). These skills are 
increasingly viewed as essential transferable skills for globalised workplaces (Jones, 2013; Oliver \& Jorre de St Jorre, 2018).

More concretely for graduates with study abroad experience, experiential learning becomes a way to demonstrate achievement of employability skills and advantages participants relative to peers with only local and subject-specific knowledge (Crossman \& Clarke, 2010; Potts, 2015). Some research points towards mobile students being more often employed in higher managerial positions in the private sector, in larger organisations and in positions with an international context (European Commission, 2014; Crossman \& Clarke, 2010), likely thanks to the qualities (intercultural adaptability, global competency, tolerance, inquisitiveness and self-awareness) that are required for these roles (Bird \& Stevens, 2013). Multinationals and 'new generation employers' seek graduates with international study experience (Prospect Marketing, 2006), although international work experience, and to a lesser extent, language skills and international networks are also valued (Crossman \& Clarke, 2010).

The above research purports the employability benefits for study abroad, but not all experiences are of equal value for prospective employers, with many preferring to a variety of different study abroad experiences (Potts, 2015), or not attributing significant employability value to study-based international experiences compared to international internships or work experience (Green et al., 2019; Kinash et al., 2016). Molony, Sowter, and Potts (2011) found that employers and recruiters in many Anglophone countries, including Australia, place a lower-than-average importance on graduates' study abroad experience and foreign language skills. Reasons cited for this are: their large multi-cultural communities, the high international mobility of youth, and the highly internationalized higher education system, which all combine to produce a base level of intercultural literacy (Molony et al., 2011, p. 17). Potts (2016) nonetheless predicts that the significance of study abroad and international experience in the Australian context will grow as more graduates, and eventually more hiring managers, come through such programmes.

The employability value of language studies - a key component of most IS degrees - is even more uncertain in the Australian context, especially in relation to the broader transferable skills. Applied linguistics researchers cite interlinguistic and intercultural capabilities, general personal development and learning about aesthetics and creativity in language use as valuable gains (Leung \& Scarino, 2016; Otsuji \& Pennycook, 2010), but these attributes cannot be conclusively linked to language-related employability. In English-dominant contexts like Australia, employers attribute less significance to foreign language learning (Molony et al., 2011) and only a few studies even mention language acquisition in the area of employability development (Crossman \& Clarke, 2010; Potts, 2015).

Much of the scholarship in this field is based on research questions posed and data gathered from those who are highly invested in study abroad and language learning. Prospective students, the broader population as well as employers are not as well represented in the literature. Where factors such as employability and 'return on investment' are important considerations for students when selecting their course and experiences, their views on the perceived value of both language learning and study abroad are important but understudied considerations for HE institutions looking to meet increasingly ambitious internationalisation and graduate employability targets.

\section{Context and methodology}

\section{Methodology and research questions}

A large Australian university offering a range of undergraduate courses combining International Studies (IS) with a professional degree (law, communications, business, etc.) as a double degree serves as a case study. A case study methodology was deemed suitable as, especially in educational research (Gulsecen \& Kubat, 2006), qualitative student accounts allow for a deeper and multifaceted exploration of an authentic issue within a particular context (Harrison, Birks, Franklin, \& 
Mills, 2017). The exploratory nature of case study research permitted a meaningful and open approach to gain a deeper understanding of students' perceptions and allowed for new perspectives to emerge. The data set fulfilled the requirements of case study analysis being complex, investigated within its setting and being contemporary (Johansson, 2003). Within the context of these features this case study seeks to answer the following research questions:

- What reasons do students give for withdrawing from the International Studies degree?

- What are their perceptions of the value of the degree for their employability?

- What can higher education institutions learn from this?

\section{Case study background}

The demographic of the double degree is mostly comprised of domestic high school leavers of which many work part time and study full time. Most students are admitted simultaneously to both degrees based on a choice made as they completed secondary study. The IS component is not a standalone course but instead structured as a complementary arts degree that adds two years to the professional course (which is generally 3 years long) consisting of compulsory language study, cultural studies about the target/host society, a year-long exchange (in the studied language) and an independent research project to be conducted while abroad. ${ }^{2}$ Students start their IS studies in their second year, after having completed a year in their professional degree.

At any point prior to their year abroad, students may withdraw from the IS stream. Over the past 15 years, withdrawal from the university's IS degrees has increased from $44 \%$ to nearly $57 \%$. To effect this change, students submit an online form and provide a supporting statement outlining their rationale for withdrawing. The nature of the statement is purely administrative (all applications are granted) and as such are often quite candid. The supporting statements for withdrawal $(n=223)$ from January 2017 to November 2018 were collated, categorised, and coded with the help of NVivo after receiving ethics approval. This process was undertaken by two researchers to ensure consistency in the interpretation of the data. Working independently, they first identified a primary rationale for seeking the change of course and cross-checked those determinations. They subsequently agreed upon an inductively derived coding schedule to facilitate a more thorough thematic analysis of the statements (Boyatzis, 1998). This second step allowed for the consideration of multiple rationales within a single request, a necessity as most students supplied several reasons and accounted for the uneven emphasis on multiple rationales within single responses. As a content analysis of the discourses that surround the value of language studies was the focus of this study, variables such as gender, degrees, age, language majors, socio-economic background were not controlled.

Of the 223 students applying to revert to a single professional degree, more than half did so at a point prior to or shortly after commencing the IS component of their double degree, which is to say at a time when their HE experience was focused on the professional studies component. Their perspectives accordingly offer a glimpse into the logics of a notoriously inaccessible demographic: those who initially showed interest in but ultimately elected against learning an additional language as part of a double degree.

\section{Findings}

Of the 223 submissions, roughly one quarter explicitly identified employability as one of the drivers of their decision; employability was the third most cited reason for withdrawal after the related reasons of increased course length and wanting to revert to a single degree. Other reasons provided include a range of academic, professional, and personal considerations often concerning the length of the degree and the year abroad.

\footnotetext{
2 The Australian system of deferred undergraduate tuition and fee assistance, including for study abroad, mitigates some of the financial considerations that are paramount in other contexts. 
As opposed to straightforward reasons such as health or finances, reasons that were categorised 'employability' encompass a range of more nuanced understandings and assumptions about the perceived value of IS degrees (as a whole or in relation to their constituent parts). Employability most often features as one of several considerations for withdrawal. Associated rationales, of which students supplied up to five in addition to employability, include the preference of a single degree, the course length, preference of postgrad studies or a shorter exchange instead of a year abroad, a simple loss of interest in IS and financial reasons. The different notions connected to employability will be presented in more detail and supported by student quotes below.

\section{Perceptions of added value}

Most frequently, employability rationales are combined with a desire to focus on the professional degree, which is seen as more enjoyable, useful, or valuable. Students typically ascribed insufficient employability value to the IS component of the combined course.

In looking at the careers that I would like to pursue I realised that I did not need the qualifications that International studies would give me. (Media Production)

I have come to the realisation throughout this semester that doing a single degree will be advantageous for the career I want to pursue in the future. (Medical Science)

The insufficiency reasoning rests on an unfavourable cost-benefit analysis; it does not add enough perceived value to the degree that students had previously chosen to justify the time, effort, and expense. Opportunity costs, however, also enter students' calculations. The notion of 'not being worth it' arises frequently in this context when students mention the length of the degree.

I do not think it would help my employment opportunities and it's not worth the extra two years. (Public Communication)

\section{International experience versus employment}

Whether framed in terms of prospects (earlier entry to graduate employment) or immediate choices (internship, current part-time work), students weigh their options and often choose employment/employability over internationalisation. These framings suggest that the two objectives are often seen as incompatible.

I don't see myself benefiting too much from international studies compared to jumping straight to the workforce. (Design: Animation)

Dropping that degree, and thus, not partaking in the compulsory In-Country Study, would allow me to not only save on money and time, but pursue alternative options in both my professional and personal life. (Law)

If I continue with this course I will only be partaking in one 3 month internship rather than two 6 month internships ... I would like to gain more practical experience in Engineering as well as focus my studies purely towards this course.

\section{Risk to employment}

In some cases, the international element of the combined course was perceived as not just insufficient in terms of a 'value-add', but as a potential risk to employment prospects. These risks are of two main types: the first, perhaps unsurprising for a generational cohort attuned to the 'fear of missing out', is being left behind classmates who make an earlier entry into the workforce, including by staying in a job that is related to the professional degree.

I am also extremely keen to get out into the workforce after completing my public communications degree and staying at university for an extra 2 years might put me behind other graduates who are looking to get jobs in the communications industry. 
To take a year off to complete the in-country study would mean quitting my job, which I believe would be an unwise career move. (Journalism)

A second perceived risk is a conclusion that the IS course will even be detrimental to future employability and is seen as distraction.

International Studies is currently a distraction to that career path and therefore I do not see the point in continuing. (Social and Political Sciences)

I personally believe that what I want to do will not be enhanced by my ability to learn about another culture/language and will possibly set me back. (Management)

\section{Employability myths}

The basis for such conclusions is not always clear. Some students cite influencers - parents, other students, co-workers, employers and even academics in their professional degree - as having informed their decision. Where academics in IS do occasionally counsel students to withdraw, their advice does not figure into rationales that cite employability.

The International studies component of the course has become less relevant after having discussions with property companies. (Property Economics)

I have discussed with family and work colleagues that it is not viable for me to study a double degree that will extend the period of study. (Property Economics)

The early point of withdrawal for many students, before they begin to engage with academics or the IS curriculum, accounts for what might be seen as misconceptions about IS motivating their withdrawal. One of these myths concerns its orienting function for either domestic or international employment, with students believing that IS was training for those seeking employment outside of Australia. Where students did not foresee their professional futures taking them further afield, they saw no purpose for undertaking the additional qualification.

With my interests becoming focused solely on career fields of Forensic Science in Australia, [I] therefore am no longer interested in studying 'International studies'.

Waning belief in the prestige or professional advantage/necessity of a double degree was also a consideration.

I chose to do a double degree because I thought it would provide me with more job prospects when I finish my degree. Not because I wanted to learn a language or go overseas. (Law)

I chose this double degree partly due to the pressure of those around me to pick an academic path that had a high ATAR [national entrance rank]. I was told I would not be reaching my full potential if I were to settle for just a communications degree. (Journalism)

In contrast to students who may have chosen the IS degree for intrinsic motivations related to the field of study, the above rationales speak to primarily extrinsic motivations about the value or prestige of a double degree. Students revisited this decision as more information, whether about these external factors or about their own internal motivations, became available to them.

\section{Perceptions of the degree and its parts}

Some students who withdrew showed limited understandings of what the course entailed, predominantly perceiving it as one of its parts, i.e. language study or year abroad. They often refer to the study abroad year as 'travel' or 'the overseas trip' and the coursework element is often perceived as only language-learning, not cultural studies or the independent research project.

The components of the International Studies course which appealed to me, such as language and travel can be found through other avenues such as exchange, which I have chosen to pursue instead. (Public Communication) 
Despite the challenge of learning a new language the only benefit of the International Studies course is the chance of living abroad for a year and obtaining a new language, two aspects that will have minimal impact on my future in the creative industries. Travelling abroad can be easily achieved in my own time. (Public Communication)

These students recognise the inherent value in international experiences and language learning, but conclude that there are more expedient ways - such as a shorter international program that can be accommodated within a single degree - to gain the attendant benefits.

Consideration of transferrable skills and attributes developed by study abroad and language such as communication, independence and intercultural capabilities are noticeably absent from students' discourse. It is perhaps in part because IS is not seen as an arts degree with an emphasis on transferable skills as students also cite a lack of connection between their two fields of study, a perception that in some cases is understood as an incompatibility.

The international studies course does not directly relate with my main degree of forensic science and I would like to put all my focus into the area of my interest.

I plan to pursue a career in business and believe it is best to focus on this aspect of my degree.

On the other end of the spectrum were students who withdrew from IS who conceded that they could see the benefit of the additional study, including in relation to employability, but were motivated to withdraw for other reasons such as financial constraints or the perceived need to focus their academic efforts on an already demanding professional degree.

\section{Discussion}

Taken on aggregate, the rationale statements supplied at the time of withdrawal indicate that degree decisions and motivations are a complex web of reasons that were also echoed in Kinash et al. (2017) and Lock and Kelly's (2020) findings on education and career decision making. Students cite a number of factors for their decisions, some of which may be contradictory or based on inclination, myths or unfounded beliefs about employment markets and what skills IS degrees enhance, but which also speak to a search for certainty. Within such rationales, however, are important insights about how (prospective) students construe the value of IS courses as the sum of only their most obvious parts: language learning and study abroad. Their perspectives reveal limited views of the employability value of these elements, especially in the domestic labour market. To gain more certainty, many withdraw in favour of a single degree that seems to offer a more conventional career path. Neither foreign language and cultural study nor the experiential pedagogical value of study abroad and the transferable nature of the learning they would gain through these experiences were significant factors enticing them to remain in the degree. Language learning was construed as a specialised skill to be used only in international, not domestic, contexts and study abroad was often likened to travel and effectively deemed to be separate from learning and employability development as experiential learning outcomes are so often not made explicit. There are consequently several myths that $\mathrm{HE}$ institutions are likely to need to counter, and counter early-on in the student life cycle, if they are to meet both their ambitious internationalisation and graduate employment targets.

\section{The importance of transferable skills}

Where two thirds of the graduate positions in Australia are open to graduates of all subject areas, breadth of knowledge and transferable skills are advantageous (Graduate Prospects, 2005, p.17). The contributions that arts and humanities degrees make to employability in terms of transferable skills such as written and spoken communication, critical analysis, research and problem solving, are nonetheless often undervalued and not recognised by students or employers. Statements from 
students withdrawing from the IS component of their degree confirm that the combination of language and cultural study and study abroad are similarly misunderstood in terms of employability: on the one hand because the degree is not seen to foster the development of transferable skills, and on the other, because these skills are perceived to be of lesser value than technical or disciplinespecific skills.

The transferability of skills, and even multidisciplinary knowledge, is greatly undervalued among these students, as it is in many humanities degrees (Dowling, Rose, \& O'Shea, 2015). Students, reifying these devisions, think of their course and subject areas as silos to which they either commit or abandon. Many IS degrees are, however, intellectually predicated on multidisciplinary, combining language study with elements of anthropology, sociology, history, politics, linguistics, and communication among others. Further, the classes in many IS degrees are likely to attract students both elective and fully-enrolled - from a variety of fields where students find themselves collaborate in multidisciplinary groups. Classrooms accordingly become microcosms of many contemporary workplaces, as people not only from diverse personal backgrounds but also from academic or professional ones come together. Where the transfer of ideas and skills will be increasingly important in diverse workplaces and are core to innovation and progress, students are afforded important practice in this key employability skill.

\section{Changing notions of employability and the labour market}

Findings show that many students who enter university directly from high school still think about their employability in a rather traditional manner that might not reflect the many changes that work places and work practices are undergoing at the moment. The priority is minimal time spent in HE, minimal disruptions, immediate fulltime employment and a priority accorded to employer perceptions of the degree as sort of black box rather than the experiences or learning therein. Their views on the labour market, employment modes and job security also speak to a belief that they must be 'first in' and fit into a well-defined disciplinary or vocational graduate position. The importance of gaining a variety of skills and attributes that might be useful at a subsequent phase of their career is altogether absent from their accounts, as is students' thinking on their impact on communities and society as a whole.

More research into the long-term effects of study abroad and international skills will be a requisite to substantiating any claims the internationalisation-minded within HE would make about the value of their activities (Potts, 2015). Nonetheless, convincing students and their influencers to shift from short to longer term thinking about employability will be equally important.

The capabilities developed in many forms of experiential learning are, moreover, not widely assumed to accrue to students through study abroad. While experiential learning in the form of internships and practicums are routinely highlighted as boons to future employability and have seen the HE sector invest heavily in work-integrated learning (Universities Australia, 2019), learning abroad (outside of international education circles) is not typically framed as a form of experiential learning, let alone one with an employability focus. Rather, it is seen as travel or a gap year, notions that are construed as anathema to the career building activities of both study and work.

The misunderstandings, however, do not rest solely with the students. The HE sector, especially providers of undergraduate education, must also recognise that many Australian students, including some of the respondents, are already part of the workforce. Tertiary study is increasingly less of a precursor to employment (including in a specific field), than a way to enrich future prospects and career development (Jackson \& Wilton, 2017). Overseas study, which requires time away from the workplace and other commitments, consequently, becomes incompatible with current employment, which respondents saw as the surer path to professional advancement. Where students are sceptical about the role of study abroad in providing additional employability value over the longer term, cost-benefit analyses will come up short. 


\section{Limitations}

This exploratory study provides some valuable insights into students' waning motivations and explored key themes around student perceptions of the value of an IS degree as a whole and its component parts. Although many statements were analysed, we cannot claim to generalise these findings, as many variables such as specific degree combinations, demographic and social factors, and motivational aspects were not explored. As for all qualitative accounts, findings are only ever as valid as participants are introspective and candid in their responses.

This study also considers only the applications for withdrawal rather than the applications for admittance into the combined course. The applications would provide an important lens on the opposite cohort of students, arguably those who count employability as one of the reasons for undertaking an additional IS course. Two important considerations, however, motivated the choice to deal with these separately. The attrition figures grossly outnumber the countervailing applications for post-matriculation admittance into the combined course by approximately 8 to 1 . In contrast to the largely administrative nature of the statements for withdrawal, applications for admission are assessed on merit by academics and often reflect the marketing discourse of the course rather than students' and their influencers' opinions. The difference in sample sizes and the need to account for the discrepancies in purpose and audience for the statements would have introduced complications to the present study and as such, were treated separately.

Further research could investigate more correlations or possibly explore the knowledge that students have of careers pathways and how they gained this information for this specific degree. It should also be acknowledged that current cohorts, those affected by travel restrictions arising as a result of the COVID-19 pandemic, find themselves in a much different situation regarding international mobility that might have a lasting impact on future students' decision making as well.

\section{Recommendations}

The initial motivations that prompt students to elect IS courses as commencing students must be shown to align with rather than undermine their employability aims. While HE institutions may be confident in the value of IS courses as a strategy to boost employability, its success ultimately depends on corresponding student confidence. Students must have and maintain confidence in the complementarity of these objectives from the outset of their studies to persist so interventions need not only be convincing, but they must also be well-timed. International experiences, whether language study, study abroad or a combination thereof, have the potential to become more linked to employability, as the current discourses of disciplinary knowledge, skills and internships already are. Interfaces between the career or employability-focused units of universities and the student mobility or international offices, to say nothing of the role of academics in relevant disciplines, however, are often weak and present many opportunities for productive and arguably necessary collaboration.

As another important factor for their employability development, students need to be helped to articulate what skills and knowledge can be transferred to the workplace and how, even within professional learning in the HE context, they can be valuable (Green et al., 2019). One way of doing this is through reflection on learning outcomes in terms of employability and transferable skills and in thinking about professional identity early on. By increasing awareness of workplace requirements and employability skills, students can be guided to identify as valuable the skills and attitudes developed in language and culture classrooms and studying abroad (Oguro \& Mueller, 2020). Similarly, students can be prompted to anticipate the relevance and value of less conventional paths, which may include temporarily moving out of employment to develop different skills through international opportunities.

Early intervention in this space is, however, paramount. If $\mathrm{HE}$ institutions are to meet their internationalisation and employability targets and not sacrifice one for the sake of the other, they 
must do more to entice students to study languages, mobility initiatives and IS courses. Mobility offices can move away from promoting international work and study opportunities as travel (or a credit-bearing gap year) to instead promote these opportunities as assets to employability. Changing the pre-departure discourse to one of career-value provides extrinsic reinforcement of intrinsic motivation rather than mistakenly (but for a matter of timing) pitting employability concerns against an initial desire to learn a language and experience other cultures. A key plank in this strategy will be to support those who had such experiences to translate their learning into terms that resonate with employers and their employability trajectory, as well as those they influence. High school teachers, parents, employers (including of student interns and cadets) who have themselves benefitted from IS courses or elements thereof are essential advocates for the second (and subsequent) generations of successful IS graduates, as they are able to provide this intervention before the decision to withdraw is made.

\section{Conclusion}

Employability is a significant and increasingly important factor for HE students when choosing a course and options within a course, such as electives and study abroad. HE providers are increasingly attuned to such concerns, but also seek to accommodate priorities such as internationalisation and student mobility that may be perceived to be at odds with the employability agenda. While those within international education have long touted and have amassed considerable evidence for the academic, personal, and professional benefits that accrue to those who study languages and study abroad, such messages are still not reaching (prospective) students and their influencers and are driving decreasing enrolments and hesitation about international opportunities. Myths about the limited or even negative value of IS degrees and their constituent parts (language and cultural study and study abroad) persist among peers, can be unwittingly reinforced, and not only deter students from applying to such programs in the first place, but also cause them to abandon their initial motivations in favour of the practicalities of current and future employment. Recent events are likely to exacerbate the issue, as mobility restrictions and safety concerns are now further disincentives to international opportunities. The field will have to react to these demands by creating more hybrid and inclusive ways of delivering these experiences.

In a HE context where internationalisation is also a priority with increasingly quantified targets, the promotion of both employability and internationalisation requires an understanding of these myths. They must in turn be countered via a concerted effort - encompassing not just academics in 'international fields' and mobility offices, but also careers services and the marketing arms of institutions - to make employability and internationalisation two sides of the same coin. 'Curriculum-enmeshed interventions' (Kinash, 2020) will be essential to attaining the range of institutional objectives and equipping students with the variety of skills, knowledge, and experience they will need to secure employment and succeed professionally.

\section{References}

Accenture (2014). What awaits 2014 grads in the working world? Retrieved from https://www.accenture.com/in-en/ /media/Accenture/Conversion-Assets/DotCom/ Documents/Global/PDF/Strategy 3/Accenture-2014-College-Graduates-Survey-Infographic.pdf

Arcidiacono, P., Hotz, V., \& Kang, S. (2012). Modelling college major choices using elicited measures of expectations and counterfactuals. Journal of Econometrics, 166(1), 3-16. https://doi:2010.1016/i.jeconom.2011.06.002

Asia Education Foundation (2014). Senior secondary languages education research project. Asia Education Foundation. https://docs.education.gov.au/system/ files/doc/other/ senior secondary languages education research project final.pdf

Australian Education International. (2010). International graduate outcomes and employer perceptions. Australian Government Department of Education and Training. 
Australian Graduate Outcome Survey. (2016). Impact of study abroad. Australian Government Department of Education and Training.

Baik, C., Naylor, R., \& Arkoudis, S. (2015). The first year experience in Australian universities: Findings from two decades, 1994-2014. Melbourne Centre for the Study of Higher Education. The University of Melbourne.

Baldry, S., Märtsin, M., \& Eivers, A. (2018). Traveling without a destination? A dialogical analysis of professional identity construction among Australian double degree psychology students. Identity, 18(2), 94-108. https://doi.org/10.1080/15283488.2018.1447483

Bird, A., \& Stevens, M. J. (2013). Assessing global leadership competencies. In M. E. Mendenhall., J. Osland, A. Bird, G.R. Oddou, M. J. Stevens, M. Maznevski, \&G. K. Stahl (Eds.). Global leadership: Research, practice, and development (pp. 113-139). NY: Routledge.

Boyatzis, R. E. (1998). Transforming qualitative information: Thematic analysis and code development. 2 nd ed. USA: SAGE.

Bridgstock, R. (2016). Graduate employability 2.0: Social networks for learning. Discussion Paper. http://www.graduateemployability2-0.com/resources/articles

British Council. (2017). Broadening Horizons 2017: Addressing the needs of a new generation. www.britishcouncil.org/education-intelligence.

Campbell, E., \& Storch, N. (2011).The changing face of motivation: A study of second language learners' motivation over time. Australian Review of Applied Linguistics, 34(2), 166-92. https://doi.org/10.1075/aral.34.2.03cam

Cardwell, P. J. (2019). Does studying abroad help academic achievement? European Journal of Higher Education, 10(2), 147-163. https://doi:2010.1080/21568235.2019.1573695

Clarke, M. (2018). Rethinking graduate employability: The role of capital, individual attributes and context. Studies in Higher Education, 43(11), 1923-37. https://www.tandfonline.com/doi/abs/10.1080/03075079.2017.1294152

Crossman, J.E., \& Clarke, M. (2010). International experience and graduate employability: Stakeholder perceptions on the connection. Higher Education, 59, 599-613. https://link.springer.com/article/10.1007/s10734-009-9268-z

Culver, S. M., Puri, I. K., Spinelli, G., DePauw, K.P., \& Dooley, J. E. (2011). Collaborative dual-degree programs and value added for students: Lessons learned through the evaluate-e project. Journal of Studies in International Education, 16(1), 40-61. https://doi:2010.1177/1028315311403934

Cushner, K., \& Karim, A. (2004). Study abroad at the university level. In D. Landis, J.M. Bennett, \& M.J. Bennett (Eds.), Handbook of Intercultural Training, (pp. 289-308). California: Sage.

Daly, A.J. (2011). Determinants of participating in Australian university student exchange programmes. Journal of Research in International Education, 10(1), 58-70.

Daly A. J., \& Barker M.C. (2005). Australian and New Zealand university students' participation in international exchange programs. Journal of Studies in International Education, 9(1), 26-41.

Daniels, L., Stewart, T., Stupnisky, T.R., Perry, R., \& LoVerso, T. (2011). Relieving career anxiety and indecision: The role of undergraduate students' perceived control and faculty affiliations. Social Psychology of Education, 14(3), 409-426.

Department of Education, Employment \& Training. (2019). Research snapshot. International mobility of Australian university students. https://internationaleducation.gov.au/research/researchsnapshots/pages/default.aspx

Dowling, D., Rose, S., \& O'Shea, E. (2015). Reconsidering humanities programmes in Australian universities Embedding a new approach to strengthen the employability of humanities graduates by empowering them as 'Global Citizens'. Social Alternatives, 34(2), 52-62.

Dwyer, M., \& Peters, C. K. (2004). The benefits of study abroad. Transitions Abroad, 37. Retrieved from https://www.transitionsabroad.com/ publications/magazine/0403/benefits study abroad.shtml

European Commission. (2014). The Erasmus impact study. Luxembourg. https://doi.org/10.2766/75468.

Farrugia, C., \& Sanger, J. (2017). Gaining an employment edge: The impact of study abroad on 21st century skills \& career prospects in the United States. IIE Center for Academic Mobility Research Impact.

Fornasiero, J., Reed, S. M. A., Amery, R., Enomoto, K., Xu, H. L., \& Bouvet, É. (Eds.). (2020). Intersections in language planning and policy: Establishing connections in languages and culture. Switzerland: Springer.

Forsey, M., Broomhall, S., \& Davis, J. (2012). Broadening the mind? Australian student reflections on the experience of overseas study. Journal of Studies in International Education, 16(2), 128-139. https://doi:2010.1177/1028315311407511

Fry, G. W., Paige, R. M., Jon, J. E., Dillow, J., \& Nam, K. A. (2009). Study abroad and its transformative power. (Occasional Paper No. 32). NY: Council on International Education Exchange. 
Gayton, A. M. (2018). A context-specific approach to L2 motivation in Anglophone settings: A first step towards theory development. The Language Learning Journal, 46(4), 384-397.

https://doi.org/10.1080/09571736.2015.113008

Gulsecen, S., \& Kubat, A., (2006).Teaching ICT to teacher candidates using PBL: A qualitative and quantitative evaluation. Educational Technology \& Society, 9(2), 96-106.

Graduate Prospects. (2005/6). Prospects directory salary and vacancy survey, Graduate Market Trends (Winter), Graduate Prospects (pp. 11-17), Manchester.

Green, W., King, E., \& Gallagher, J. (2019). How can international learning experiences enhance employability? Critical insights from new graduates and the people who employ them. In R. Coelen \& C. Gribble (Eds.), Internationalization and Employability in Higher Education, (pp. 25-38). UK: Routledge.

Greenbank, P. (2011). Improving the process of career decision making: An action research approach. Education + Training, 53(4), 252-266.

Hajek, J., \& Baldwin, J. (2020) Remembering language studies in Australian universities: An Italian case study.

In J. Fornasiero, S.M.A. Reed, R. Amery, K. Enomoto, H.L. Xu., \& É. Bouvet (Eds.). (2020). Intersections in language planning and policy: Establishing connections in languages and culture (pp. 65-82). Switzerland: Springer.

Harrison, H., Birks, M., Franklin, R., \& Mills, J. (2017). Cast study research: Foundations and methodological orientations. Forum: Qualitative Social Research, 18(1). Available at: https://www.qualitativeresearch.net/index.php/fqs/article/view/2655/4079

Heller, M., \& Duchêne, A. (2012). Pride and profit: Changing discourses of language, capital and nation-state. In A. Duchêne \& M. Heller (Eds.), Language in late capitalism (pp. 1-21). NY: Routledge.

Holmes, L. (2013). Competing perspectives on graduate employability: Possession, position or process? Studies in Higher Education, 38(4), 538-554. https://doi:2010.1080/03075079.2011.587140

Humlum, M., Kleinjans, K., \& Nielsen, H. (2012). An economic analysis of identity and career choice. Economic Inquiry, 50(1), 39-61. https://doi:2010.1111/j.1465-7295.2009.00234.x

Jackson, D. (2016). Modelling graduate skill transfer from university to the workplace. Journal of Education and Work, 29(2), 199-231. https://doi.org/10.1080/13639080.2014.907486

Jackson, D., \& Wilton, N. (2017). Career choice status among undergraduates and the influence of career management competencies and perceived employability, Journal of Education and Work, 30(5), 552569. https://doi:2010.1080/13639080.2016.1255314

Jackson, J. (2011). Host language proficiency, intercultural sensitivity, and study abroad. Frontiers: The Interdisciplinary Journal of Study Abroad, 21(1), 167-189.

Johansson, R. (2003). Case study methodology. A key note speech at the International Conference: Methodologies in Housing Research, Stockholm, 22-24 September 2003. Available at: http://www.psyking.net/HTMLobj-3839/Case Study Methodology- Rolf Johansson ver 2.pdf

Johnson, M., \& Anderson, C. (2019). The impact of education abroad on competency development. In R. Coelen \& C. Gribble (Eds.), Internationalization and Employability in Higher Education, (pp. 49-58). NY: Routledge.

Jones, E. (2013). Internationalization and employability: The role of intercultural experiences in the development of transferable skills. Public Money \& Management, 33(2), 95-104. https://doi:2010.1080/09540962.2013.763416\%20

Kinash, S. (2020). For university educators: How to embed employability and career-perspectives in the curriculum. Online presentation hosted by University of Melbourne, 29 July 2020.

Kinash, S., Crane, L., Judd, M., \& Knight, C. (2016). Discrepant stakeholder perspectives on graduate employability strategies, Higher Education Research \& Development, 35(5), 951-967. https://doi.org/10.1080/07294360.2016.1139555

Kinash, S., Crane, L., Capper, J., Young, M., \& Stark, A. (2017). When do university students and graduates know what careers they want: A research-derived framework. Journal of Teaching and Learning for Graduate Employability 8(1), 3-21. https://doi.org/10.21153/jtlge2017vol8no1art584

Kramsch, C. (2014). Teaching foreign languages in an era of globalization: Introduction. The Modern Language Journal, 98(1), 296-311. https://doi.org/10.1111/j.1540-4781.2014.12057.x

Leach, L., \& Zepke, N. (2005). Student decision-making by prospective tertiary students: A review of existing New Zealand and overseas literature. Ministry of Education New Zealand. www.minedu.govt.nz/goto/tertiaryanalysis

Leung, C., \& Scarino, A. (2016). Reconceptualizing the nature of goals and outcomes in language/s education. The Modern Language Journal, 100 (Supplement 2016), https://doi:2010.1111/modl.12300 
Lock, E., \& Kelly, K. (2020). Ignorance is risk: An exploratory investigation of Australian higher education students' perceptions of their education-employment pathways. Journal of Teaching and Learning for Graduate Employability, 11(1), 22-36. https://doi.org/10.21153/itlge2020vol11no1art894

Mcllveen, P., Brooks, S., Licjtenberg, A., Smith, M., Torjul, P., \& Tyler, J. (2011). Perceptions of career development learning and work-integrated learning in Australian higher education. Australian Journal of Career Development, 20(1), 32-41. https://doi:2010.1177/103841621102000105

Medina-López-Portillo, A. (2004). Intercultural learning assessment: The link between program duration and the development of intercultural sensitivity. Frontiers: The Interdisciplinary Journal of Study Abroad, 10, 179-200.

Mendoza, A., \& Phung, H. (2019). Motivation to learn languages other than English: A critical research synthesis. Foreign Language Annals 52(1), 121-40. https://doi:2010.1111/flan.12380

Moloney, R. (July, 3, 2018). Learning languages early is key to making Australia more multilingual. The Conversation. https://theconversation.com/learning-languages-early-is-key-to-making-australia-moremultilingual-99085

Molony, J., Sowter, B., \& Potts, P. (2011). QS Global Employer Survey Report 2011. QS Quacquarelli Symonds Ltd. https://content.qs.com/qs/qs-global-employer-survey-2011.pdf.

Mueller, B. (2021). It's all in the mind: Developing new ways of thinking and acting during a semester abroad: An Australian case study. In E. Mikulec, S. Potempa \& K. Pike Inman (Eds.), Education Abroad: Learning Environments in a Global Context (pp. 19-37). Information Age Publishing.

Munro, K. (June, 1, 2016). Why students are turning away from learning foreign languages. Sydney Morning Herald. https://www.smh.com.au/education/why-students-are-turning-away-from-learning-foreignlanguages-20160610-gpg6ek.html

Oakes, L. (2013). Foreign language learning in a 'monoglot culture': Motivational variables amongst students of French and Spanish at an English university. System: An International Journal of Educational Technology and Applied Linguistics, 41(1), 178-191. https://doi 10.1016/j.system. 2013.01.019

Oguro, S., \& Mueller, B. (2020). Learning abroad and graduate employability: Challenges articulating international learning outcomes. In E. Heinrich \& R. Bourke (Eds.), Research and Development in Higher Education: Next generation, Higher Education: Challenges, Changes and Opportunities, 42 (pp 85 - 93). Australia: HERDSA.

https://opus.lib.uts.edu.au/bitstream/10453/140018/1/Oguro\%20and\%20Mueller\%202020 Learning\% 20Abroad\%20and\%20Graduate\%20Employability.pdf

Oliver, B., \& Jorre de St Jorre, T. (2018). Graduate attributes for 2020 and beyond: Recommendations for Australian higher education providers. Higher Education Research \& Development, 37(4), 821-836. https://doi:2010.1080/07294360.2018.1446415

Otsuji, E., \& Pennycook, A. (2010). Metro-lingualism: Fixity, fluidity and language in flux. International Journal of Multilingualism, 7, 240-254. https://doi10.1080/14790710903414331

Parks, A., Mills, J., Weber, D., \& Westwell, M. (2017). Ready or not, here I come! Learning to support year 12 students' university study choices. Conference Proceedings, HERDSA Conference, 2017.

Parliament of the Commonwealth of Australia. (2020). Higher Education Support Amendment (Job-Ready Graduates and Supporting Regional and Remote Students) Bill 2020. https://parlinfo.aph.gov.au/parllnfo/download/legislation/bills/r6584 aspassed/toc pdf/20107b01.pdf; fileType=application $\% 2 \mathrm{Fpdf}$

Potts, D. (2015). Understanding the early career benefits of learning abroad programs. Journal of Studies in International Education, 19(5), 441-459. https://doi.org/10.1177/1028315315579241

Potts, D. (2016). Outcomes of learning abroad programs. International Education Association of Australia. https://www.ieaa.org.au/documents/item/750.

Potts, D. (2018). Learning abroad and employability: Researching the connections. IEEA Research Digest. https://www.ieaa.org.au/documents/item/1267

Prospect Marketing. (2006). The attitudes and perceptions of Australian employers towards an overseas study experience. Melbourne, Australia: Queensland Education and Training International and the International Education Association of Australia.

Thompson, A. (2017). Language learning motivation in the United States: An examination of language choice and multilingualism. The Modern Language Journal, 101(3), 483-500. https://doi:2010.1111/modl.12409

Trede, F., Macklin, R., \& Bridges, D. (2012). Professional identity development: A review of the higher education literature. Studies in Higher Education, 37(3), 365-384, https://10.1080/03075079.2010.521237 
Universities Australia (2016). More Australian students see the value of study abroad. https://www.universitiesaustralia.edu.au/Media-and-Events/media-releases/More-Australian-studentssee-the-value-of-study-abroad\#.XJLgp7hxXIU

Universities Australia (2019). Career Ready Graduates. http://acen.edu.au/career-ready-graduates-ua-report/ Young B., \& Harper C. (2004). Australian student mobility through exchange: A Universities 21 case study. Paper presented at the 18th IDP Australian International Education Conference, Sydney, 5-8 October.

Young, E. (June, 5, 2018). Should we insist Aussie kids learn a second language? https://www.sbs.com.au/news/should-we-insist-aussie-kids-learn-a-second-language

Yorke, M. (2006). Employability in higher education: what it is-what it is not (Vol. 1). York: Higher Education Academy. 